\title{
Phytochemical Screening and Evaluation of the Antioxidant Activity of Ficus capreifolia Leaf Extract via in-vitro Models
}

\author{
Tetam Jack Gbenenee $^{1^{*}}$, Ndokiari Boisa ${ }^{1}$ and Tebekeme Okoko ${ }^{1,2}$ \\ ${ }^{1}$ Department of Chemistry, Faculty of Science, Rivers State University, Port-Harcourt, Nigeria. \\ ${ }^{2}$ Department of Biochemistry, Faculty of Basic Medical Sciences, Niger Delta University, \\ Wilberforce Island, Bayelsa State, Nigeria.
}

\begin{abstract}
Authors' contributions
This work was carried out in collaboration between all authors. Author TO designed the study while author TJG performed the laboratory analysis under the supervision of author NB. Author TJG wrote the first draft while authors TO and NB managed the literature and the statistical analysis. All authors read and approved the final manuscript.

Article Information

DOI: $10.9734 /$ IJBCRR/2017/34138 Editor(s):

(1) Shadaan Abid, Department of Internal Medicine, UT Southwestern Medical Center, Dallas, Texas, USA.

Reviewers:

(1) Muhammad Ali, Kano University of Science and Technology, Nigeria.

(2) Sattya Narayan Talukdar, Primeasia University, Bangladesh. Complete Peer review History: http://www.sciencedomain.org/review-history/19302
\end{abstract}

Original Research Article

Received 15 $5^{\text {th }}$ May 2017

Accepted $30^{\text {th }}$ May 2017

Published $2^{\text {nd }}$ June 2017

\section{ABSTRACT}

Aims: To carry out preliminary phytochemical screening and determine the antioxidant ability of Ficus capreifolia leaf extract.

Study Design: The study was designed to evaluate the phytochemical profile of Ficus capreifolia leaf and the potential antioxidant activity and comparing to reference antioxidant vitamin C.

Place and Duration of Study: The research was done in the Department of Chemistry, Rivers State University from May to August 2016.

Methodology: The extract was screened for the presence of some phytochemicals. Thereafter, the antioxidant potential was determined by assessing the hydrogen peroxide scavenging ability, hydroxyl radical scavenging activity and ferrous ion reducing ability and comparing them to the corresponding ability of vitamin C.

Results: Phytochemicals detected include tannins, carotenoids, alkaloids, flavonoids, steroids, cardiac glycosides and polyphenols. The extract also scavenged hydrogen peroxide, hydroxyl 
radicals and also reduced ferrous ions significantly when compared to vitamin C.

Conclusion: The leaf extract exhibited significant antioxidant activities which could be ascribed to antioxidant phytochemicals such as flavonoids, polyphenols which were detected. This corroborates the reported traditional use of the plant and can be further exploited pharmacologically.

Keywords: Ficus capreifolia; phytochemical; hydrogen peroxide; vitamin C; flavonoids.

\section{INTRODUCTION}

The utilization of oxygen is key to aerobic metabolism however it is a paradox that reactive oxygen species (ROS) are responsible for the pathogenesis of many disorders [1]. These ROS (both free radicals and other non-radical species) damage membrane lipids, cause DNA mutations and protein damage which could be sporadic. Metabolically, the body has efficient mechanisms to mask, scavenge or dismutate these ROS. The production of these ROS is in fact indispensable for life hence there is a balance between ROS production and antioxidation. Should an imbalance occur (in favour of ROS production), a condition known as oxidative stress occurs and the consequences could be cancer, aging, cardiovascular disease, liver injury etc [2-4]. Plants are rich sources of potential antioxidant compounds hence the intake of diets rich in plants (especially fruits, cereals, vegetables) has been encouraged.

Ficus capreifolia (Moraceae) is a fig shrub that grows in the tropical regions of Africa. The plant (also known as sandpaper fig) grows to about 7 $\mathrm{cm}$ in height [5]. The roots and leaves of the plant have been used to treat Schistosomal infections and diabetes [6]. Despite being of potential medicinal value, the plant is grossly underutilized coupled with the limited literature available on studies of the plant. Based on this, this work investigates the antioxidant potential of the Ficus capreifolia leaves using some in vitro models. The leaves were also screened for the presence of some phytochemicals.

\section{MATERIALS AND METHODS}

\subsection{Chemicals and Reagents}

All chemicals and reagents were of analytical grade thus used without further purification. All buffers and solutions were prepared using deionized water and used within 24 hrs.

\subsection{Plant Collection and Identification}

The leaves of Ficus capreifolia were harvested from its natural environment in Oto-Udu, Udu
Local Government Area, Delta State, Nigeria. The plant was identified and authenticated by Prof. (Mrs.) Green of the Department of Applied and Environmental Biology, Rivers State University, Port Harcourt. A voucher specimen (F. capreifolia-2016-05) was deposited at their herbarium.

\subsection{Preparation of Extract}

Fresh leaves of Ficus caprecfolia were properly washed with deionized water to remove dirt. The leaves were sundried and pulverized using a warring blender. The extraction was done using Batch Extraction Method with methanol as the extracting solvent. The powdered sample $(200 \mathrm{~g})$ was soaked in $1 \mathrm{~L}$ of absolute methanol for 72 hours. The supernatant was collected and filtered using Whatman filter paper and concentrated using a rotary evaporator set at $400^{\circ} \mathrm{C}$ to give a residue. Different concentrations $(0.25,0.50,1.00$ and $2.00 \mathrm{mg} / \mathrm{ml})$ of the extract were prepared and subjected to further analysis.

\subsection{Preliminary Phytochemical Analysis}

The extract was screened for the presence of alkaloids, flavonoids, polyphenols, saponins, steroids, tannins, cardiac glycosides and carotenoids according to the methods of Bera et al. [4] and Edeoga et al. [7].

\subsection{Hydrogen Peroxide Scavenging Activity}

Hydrogen peroxide scavenging activity was performed by replacement titration as reported by Zhao et al. [8] with some modifications. Briefly $1 \mathrm{ml}$ of hydrogen peroxide $(0.1 \mathrm{M}), 1 \mathrm{ml}$ of the extract, $3 \mathrm{ml}$ of ammonium molydate (3\%), $10 \mathrm{ml}$ of $2 \mathrm{M}$ sulphuric acid and $7 \mathrm{ml}$ of potassium iodide $(1.8 \mathrm{M})$ were introduced into a conical flask. This was then titrated against sodium thiosulphate of (5.09 M). Disappearance of the yellow colour indicated end point of the reaction. The hydrogen peroxide scavenging activity of was expressed as a percentage thus: 
\% scavenging activity

$=\underline{\mathrm{V}}_{\text {control }} \frac{-\mathrm{V}_{\text {sample }}}{\mathrm{V}_{\text {control }}} \times 100 \%$

\subsection{Hydroxyl Radicals Activity \\ Scavenging}

Hydroxyl radical scavenging activity was investigated using the method described by Bera et al. [4]. Briefly, $1 \mathrm{ml}$ of phosphate buffer (0.2 M, $\mathrm{pH} 7.2), 1 \mathrm{ml}$ of test solution, $0.02 \mathrm{ml}$ of ferric chloride $(0.02 \mathrm{M})$ and $0.05 \mathrm{ml}$ of phenanthroline $(0.04 \mathrm{M})$ were introduce into a test tube. Reaction was initiated by the addition of $0.05 \mathrm{ml}$ of $7 \mathrm{mM}$ hydrogen peroxide. After $5 \mathrm{~min}$ of incubation at room temperature, absorbance was measured at $560 \mathrm{~nm}$ using a UV spectrophotometer. Hydroxyl radical scavenging activity was expressed as relative scavenging activity and calculated using the relation:

$\%$ scavenging activity

$$
=\frac{A_{\text {control }}-A_{\text {sample }}}{A_{\text {control }}}=100 \%
$$

\subsection{Reducing Ability}

The ability of the extract to reduce $\mathrm{Fe}^{3+}$ was investigated according to Oyaizu [9] as modified by Okoko and Ere [10]. Test solution $(0.5 \mathrm{ml})$ was mixed with $0.5 \mathrm{ml}$ of phosphate buffer $(0.2 \mathrm{M}$ $\mathrm{pH} 6.6$ ) and $0.5 \mathrm{ml}$ of potassium ferricyanide $(1 \%)$ and incubated at $50^{\circ} \mathrm{C}$. After incubation for 20 minutes, $0.5 \mathrm{ml}$ of trichloroacetic acid (10\%) was added and centrifuged for 10 minutes at $3000 \mathrm{rpm}$. A portion of the upper layer $(0.5 \mathrm{ml})$ was mixed with $0.5 \mathrm{ml}$ distilled water and $0.1 \mathrm{ml}$ ferric chloride $(0.1 \%)$. After $10 \mathrm{~min}$ incubation at room temperature, absorbance was measure at $700 \mathrm{~nm}$. Increase in absorbance indicated greater reducing ability.

\subsection{Statistical Analysis}

Representative readings were expressed as mean \pm S.E from four replicates. Data were analyzed using either a student's t-test (for comparison between two groups) or analysis of variance (ANOVA) for multiple comparisons. Confidence exhibited at $p<0.05$ was considered statistically significant. Vitamin $C$ was used as the reference control for the antioxidant assessment.

\section{RESULTS}

Phytochemical analysis of the Ficus capreifolia (leaves) revealed the presence of tannins, carotenoids, alkaloids, steroids, polyphenols, flavonoids and cardiac glycosides. However, saponins were not detected (Table 1).

Table 1. Photochemicals screening test for active components in the Ficus capreifolia extract

\begin{tabular}{ll}
\hline Active compound & Evidence \\
\hline Tannis & + \\
Carotenoids & + \\
Alkaloids & + \\
Flavonoids & + \\
Saponins & - \\
Steroids & + \\
Cardiac glycoside & + \\
Polyphenol & + \\
\hline \multicolumn{2}{c}{$\quad$ detected; - not detected }
\end{tabular}

The hydrogen peroxide scavenging ability, hydroxyl radical scavenging ability and the ability of the extract to reduce ferric ion are shown in Figs. 1, 2 and 3. The extract possessed significant ability to scavenge hydrogen peroxide, hydroxyl radical and to reduce ferric ions when compared to the reference compound (vitamin $\mathrm{C}$ ). Though the responses seem to be concentration-dependent in all cases, the variations were not significant in many cases. The variation of hydrogen peroxide scavenging ability between $0.25 \mathrm{mg} / \mathrm{ml}$ and $0.5 \mathrm{mg} / \mathrm{ml}$ was significant $(p<0.05)$ while it was not significant $(p>0.05$ ) from $0.5 \mathrm{mg} / \mathrm{ml}$ to $2.0 \mathrm{mg} / \mathrm{ml}$. For the hydroxyl radical scavenging activity, there was no statistical difference among the various concentrations $(p>0.05)$. For the reducing ability, the difference between $0.25 \mathrm{mg} / \mathrm{ml}$ and $0.5 \mathrm{mg} / \mathrm{ml}$ was significant $(p<0.05)$, not significant between $0.5 \mathrm{mg} / \mathrm{ml}$ and $1.0 \mathrm{mg} / \mathrm{ml}$ but significant difference $(p<0.05)$ was exhibited between $1.0 \mathrm{mg} / \mathrm{ml}$ and $2.0 \mathrm{mg} / \mathrm{ml}$.

\section{DISCUSSION}

The production of ROS and antioxidation are not mutually exclusive as long as life exists. Various physical and chemical processes induce and activate oxidant producing enzymes such as NADPH oxidase, xanthine oxidase etc. These enzymatic reactions produce ROS such as superoxide radical, nitric oxide, hydrogen peroxide, peroxynitrates [11]. The body has efficient mechanisms (both enzymatic and nonenzymatic) to keep these reactive species in check since they are products of essential processes. However, these ROS could be over produced due to a number of factors and the 
consequences are damage to tissues, DNA, proteins which are predisposing to cancer, cardiovascular diseases, diabetes, ageing, neuro degradative disorders, stroke, gastrointestinal diseases, etc [12-15]. Thus antioxidant supplementation is necessary to maintain redox balance. Plants are the main sources of these antioxidants. Phytonutrients have been recommended to be effective substitutes for most synthetic products since there are reported lessfrequent side effects following the consumption of plants or plant-derived products [16].

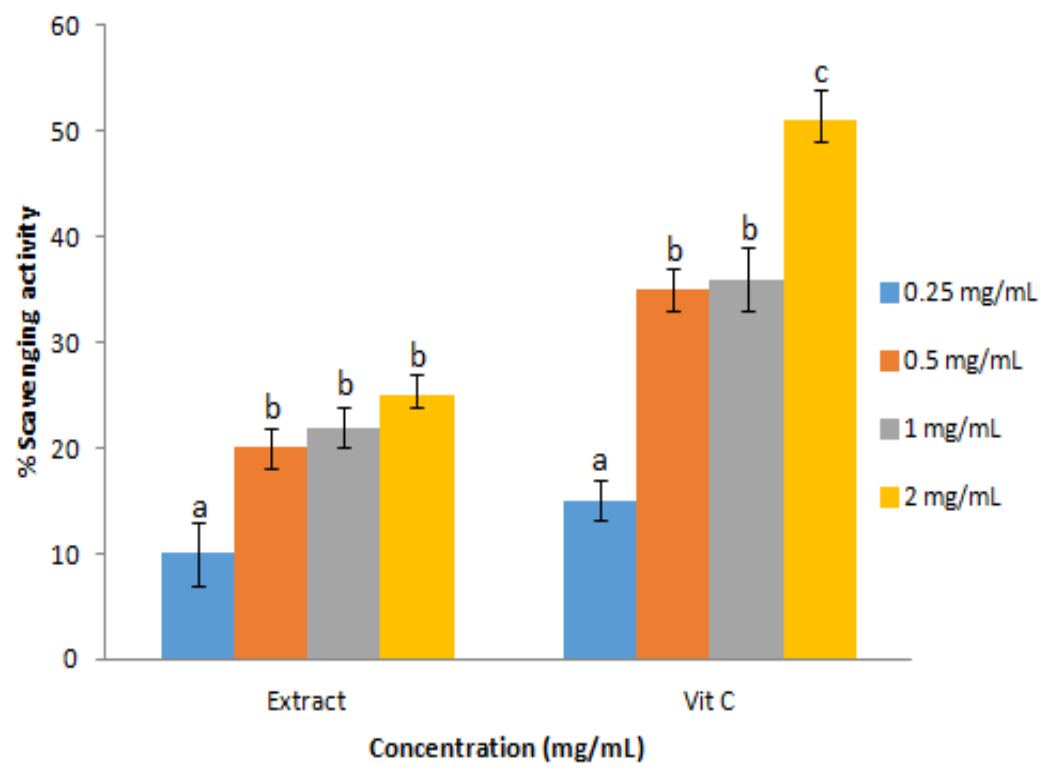

Fig. 1. Hydrogen peroxide scavenging activity of Ficus capreifolia leaf and vitamin C Each bar represents Mean \pm SEM of four replicates. For each set of bars, values having different superscript letters differ significantly $(p<0.05)$

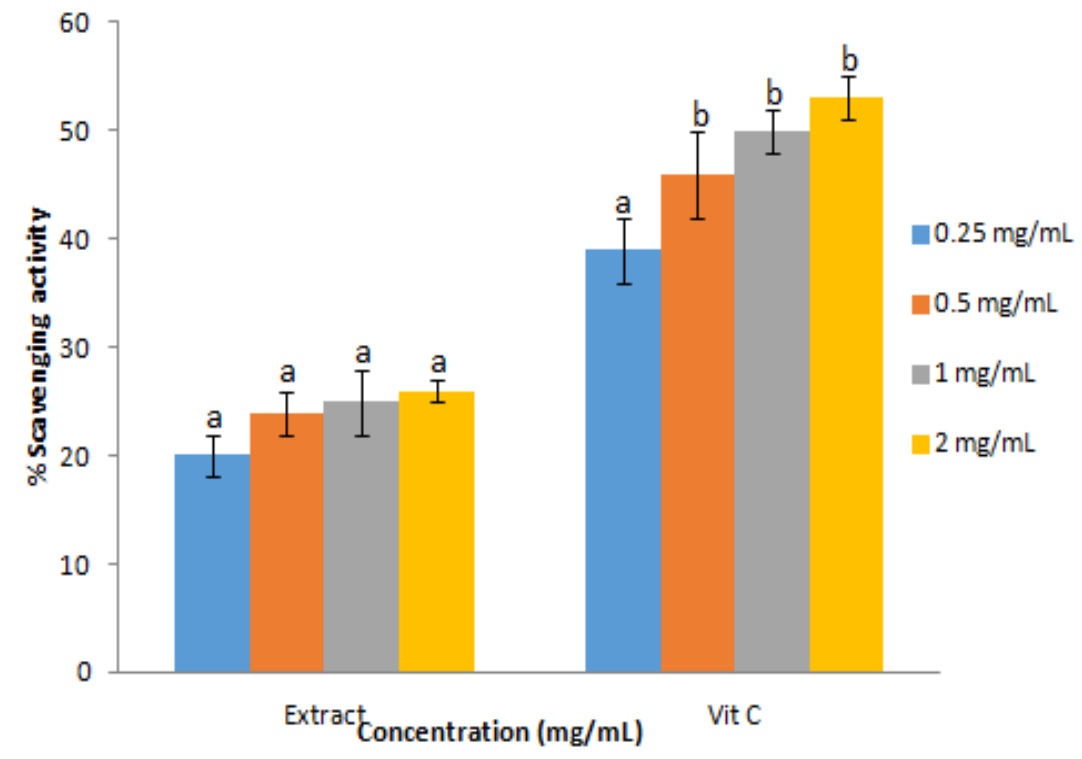

Fig. 2. Hydroxyl radical scavenging ability of Ficus capreifolia and vitamin C

Each bar represents Mean \pm SEM of four replicates. For each set of bars, values having different superscript letters differ significantly $(p<0.05)$ 


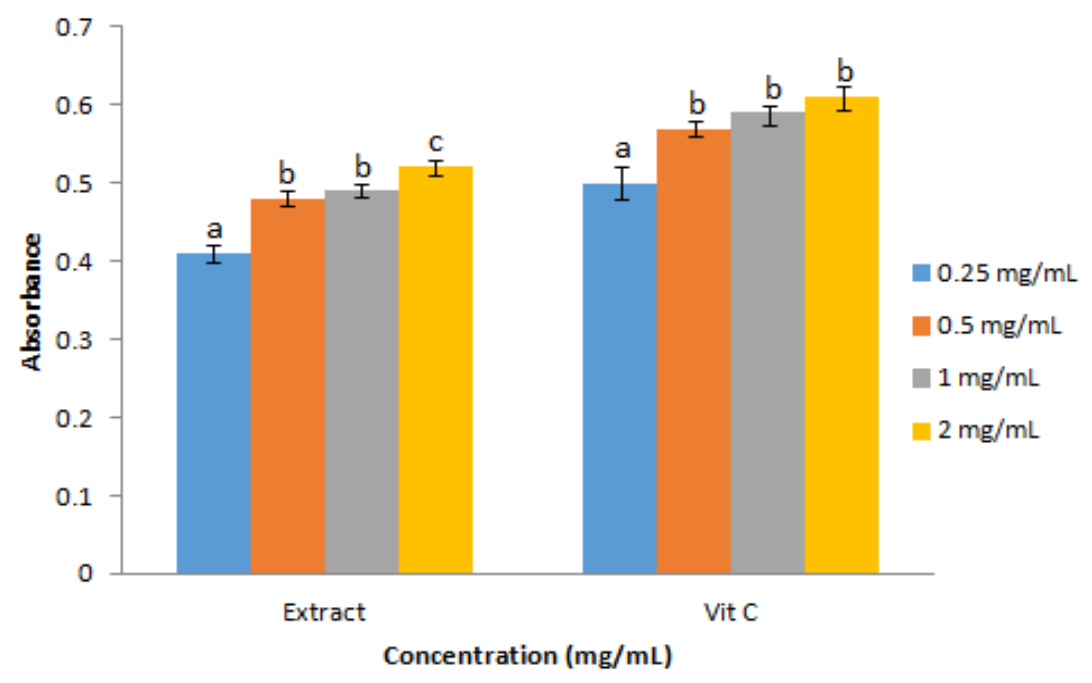

Fig. 3. Reducing ability of Ficus capreifolia and vitamin C

Each bar represents Mean \pm SEM of four replicates. For each set of bars, values having different superscript letters differ significantly $(p<0.05)$

Hydrogen peroxide is a potent oxidant produced via phagocytosis and in reactions catalyzed by xanthine oxidase, superoxide dismutase [17]. Though converted to water by catalase or gluthathione peroxidase, overproduction damages various cellular targets due to its diffusible nature [17-19].

The study revealed that Ficus capreifolia leaf scavenged hydrogen peroxide which was significant when compared to vitamin C (Fig. 1).

The hydroxyl radical is the most harmful in the biosystem because of its non-selective reactivity [20-21]. In the presence of transition metal ions (such as $\mathrm{Fe}^{3+}$ and $\mathrm{Cu}^{2+}$ ), hydrogen peroxide could generate hydroxyl radical via the Fenton reaction [22]. Thus the reduction of these redox active transition metal ions and the scavenging of the hydroxyl radical are indispensible at reducing free radical induced damage. Ficus capreifolia extract significantly scavenged hydroxyl radical and also reduced ferric ions. This ability could be due to important phytochemicals inherent in the plant. Preliminary phytochemical screening revealed the presence of tannins, carotenoids, alkaloids, steroids, polyphenols, flavonoids and cardiac glycosides (Table 1). Flavonoids and other polyphenols have been reported to possess immense antioxidant potential by scavenging hydroxyl radicals, hydrogen peroxide and also possess metal reducing abilities [23-26]. Thus the intake of diet rich in flavonoids (fruits and vegetables) has been inversely associated with the development of coronary heart disease, cancer, cerebrovascular disease etc [27]. In addition to polyphenols, the antioxidant activities of alkaloids, tannins and carotenoids have also been reported [28-32]. Thus the observed in-vitro antioxidant activity could be due to synergy exhibited by the various phytochemicals. However, this is yet to be investigated.

\section{CONCLUSION}

Ficus capreifolia extract exhibited high in-vitro antioxidant and free radical scavenging potentials when compared to vitamin $C$ so could be exploited both pharmacologically and neutraceutically. The various in-vitro models indicate that Ficus capreifolia extract is a significant source of natural antioxidants, which could be helpful in preventing the progress of various diseases due to oxidative stress. Followup studies using various in-vivo models are recommended.

\section{COMPETING INTERESTS}

Authors have declared that no competing interests exist.

\section{REFERENCES}

1. Becker LB. New concepts in reactive oxygen species and cardiovascular reperfusion physiology. Cardiovasc. Res. 2004;61:461-470. 
2. Feig DI, Reid TM, Loeb LA. Reactive oxygen species in tumorigenesis. Cancer Res. 1994;54:1890s-1894s.

3. Halliwell B. Antioxidants in human health and disease. Annu Rev Nutr. 1996;16:3350 .

4. Bera TK, Chatterjee K, Ghosh D. In-vitro antioxidant properties of the hydromethanol extract of the seeds of Swietenia mahagoni (L.) Jacq. Biomarkers Genomic Medicine. 2015;7:18-24.

5. Maurin O, Davies TJ, Burrows JE, Daru $\mathrm{BH}$, Yessoufou K, Muasya AM, Bank M, Bond WJ. Savanna fire and the origins of the 'underground forests' of Africa. New Phytol. 2014;204:201-214.

6. Olaokun OO, McGaw LJ, Eloff JN, Naidoo V. Evaluation of the inhibition of carbohydrate hydrolysing enzymes, antioxidant activity and polyphenolic content of extracts of ten African Ficus species (Moraceae) used traditionally to treat diabetes. BMC Complement Altern Med. 2013;13:94.

7. Edeoga HO, Okwu DE, Mbaebie BO. Phytochemical constituents of some Nigerian medicinal plants. African $J$ Biotechnol. 2005;4:685-688.

8. Zhao GR, Xiang ZJ, Ye TX, Yuan YJ, Guo ZX. Antioxidant activities of Salvia miltiorrhiza and Panax notoginseng. Food Chem. 2006;99:767-774.

9. Oyaizu M. Studies on the products of browning reaction prepared from glucose amine. Jpn J Nutr. 1986;44:307-315.

10. Okoko T, Diepreye E. Reduction of hydrogen peroxide-induced erythrocyte damage by Carica papaya leaf extract. Asian Pacific Journal of Tropical Biomedicine. 2012;2:449-453.

11. Kim MY, Wogan GN. Mutagenesis of the supF gene of pSP189 replicating in AD293 cells co-cultivated with activated macrophages: Roles of nitric oxide and reactive oxygen species. Chem Res Toxicol. 2006;19:1483-1491.

12. Valko M, Jomova K, Rhodes CJ, Kuča K, Musílek K. Redox-and non-redox-metalinduced formation of free radicals and their role in human disease. Arch Toxicol. 2016;90:1-37.

13. Armstrong D, Stratton RD. Oxidative stress and antioxidant protection. In: The science of free radical biology and disease. John Wiley \& Sons; 2016.

14. Bhattacharyya A, Chattopadhyay R, Mitra S, Crowe SE. Oxidative stress: An essential factor in the pathogenesis of gastrointestinal mucosal diseases. Physiol Rev. 2014;94:329-354.

15. Thanan R, Oikawa S, Hiraku Y, Ohnishi S, Ma N, Pinlaor S, Yongvanit P, Kawanishi S, Murata M. Oxidative stress and its significant roles in neurodegenerative diseases and cancer. Intern $\mathrm{J}$ Mol Sc. 2014;16:193-217.

16. Hu X, Sato J, Oshida Y, Yu M, Bajotto G, Sato Y. Effect of Gosha jinki-gan (Chinese herbal medicine): Niu-che-sen-qi-wan) on insulin resistance in STZ induced diabetic rats. Diab Res Clin Pract. 2003;59:103111.

17. Desai KM, Wu L. Free radical generation by methylglyoxal in tissues. Drug Met Drug Interact. 2008;23:151-73.

18. Birben E, Sahiner UM, Sackesen C, Erzurum S, Kalayci O. Oxidative stress and antioxidant defense. World Allergy J. 2012;5:9-19.

19. Zhao XC, Zhang L, Yu XF, Lin XF, Tan C, Lu RR. Curcumin protects mouse neuroblastoma Neuro-2A cells against hydrogen-peroxide-induced oxidative stress. Food Chem. 2011;129:387-394.

20. Poeggeler B, Reiter RJ, Tan DX, Chen LD, Manchester LC. Melatonin, hydroxyl radical-mediated oxidative damage and aging: A hypothesis. J Pineal Res. 1993; 14:151-168.

21. Erel O. A novel automated method to measure total antioxidant response against potent free radical reactions. Clin Biochem. 2004;37:112-119.

22. Mostofa KMG, Sakugawa H. Simultaneous photo-induced generation of $\mathrm{Fe}^{2+}$ and $\mathrm{H}_{2} \mathrm{O}_{2}$ in rivers: An indicator for photo-Fenton reaction. J Environ Sci. 2016;47:34-38.

23. Panat NA, Maurya DK, Ghaskadbi SS, Sandur SK. Troxerutin, a plant flavonoid, protects cells against oxidative stressinduced cell death through radical scavenging mechanism. Food Chem. 2016;194:32-45.

24. da Silva Padilha CV, Miskinis GA, de Souza MEAO, Pereira GE, de Oliveira D, Bordignon-Luiz MT, dos Santos Lima M. Rapid determination of flavonoids and phenolic acids in grape juices and wines by RP-HPLC/DAD: Method validation and characterization of commercial products of the new Brazilian varieties of grape. Food Chem. 2017;228:106-115.

25. Mehrotra V, Mehrotra S, Kirar V, Shyam R, Misra K, Srivastava AK, Nandi SP. 
Antioxidant and antimicrobial activities of aqueous extract of Withania somnifera against methicillin-resistant Staphylococcus aureus. J Microbiol Biotechnol Res. 2017;1:40-45.

26. Jabeen E, Janjua NK, Ahmed S, Murtaza I, Ali T, Hameed S. Radical scavenging propensity of $\mathrm{Cu}^{2+}, \mathrm{Fe}^{3+}$ complexes of flavonoids and in-vivo radical scavenging by $\mathrm{Fe}^{3+}$-primuletin. Spectrochim. Acta Part A. 2017;171:432-438.

27. Angeloni C, Spencer JP, Leonani E, Biagi PL, Hrelia S. Role of quercetin and its in vivo metabolites in protecting $\mathrm{H} 9 \mathrm{c} 2$ cells against oxidative stress. Biochimie. 2007; 89:73-82.

28. Gülçin I, Elias R, Gepdiremen A, Chea A, Topal F. Antioxidant activity of bisbenzyliso quinoline alkaloids from Stephania rotunda: Cepharanthine and fangchinoline.
J Enzyme Inhib Med Chem. 2010;25:4453.

29. Chung HS, Woo WS. A quinolone alkaloid with antioxidant activity from the aleurone layer of anthocyanin-pigmented rice. $\mathrm{J}$ Nat Prod. 2001;64:1579-1580.

30. Gu HF, Li CM, Xu YJ, Hu WF, Chen MH, Wan QH. Structural features and antioxidant activity of tannin from persimmon pulp. Food Res Intern. 2008; 41:208-217.

31. Stahl W, Sies H. Antioxidant activity of carotenoids. Mol Aspect Med. 2003;24: 345-351.

32. Murthy KC, Vanitha A, Rajesha J, Swamy MM, Sowmya PR, Ravishankar GA. In vivo antioxidant activity of carotenoids from Dunaliella salina - a green microalgae. Life Sci. 2005;76:1381-1390.

(0) 2017 Gbenenee et al.; This is an Open Access article distributed under the terms of the Creative Commons Attribution License (http://creativecommons.org/licenses/by/4.0), which permits unrestricted use, distribution, and reproduction in any medium, provided the original work is properly cited.

Peer-review history:

The peer review history for this paper can be accessed here: http://sciencedomain.org/review-history/19302 